\title{
INFECÇÃO DO TRATO URINÁRIO
}

\author{
URINARYTRACT INFECTION
}

Osvaldo Merege Vieira Neto

Médico Assistente.Divisão de Nefrologia. Departamento de Clínica Médica. Faculdade de Medicina de Ribeirão Preto - USP CorReSPONDÊNCIA: Campus Universitário - CEP 14.048-900 Ribeirão Preto - SP - Email: omvieira@uol.com.br

VIEIRA NETO OM. Infecção do trato urinário. Medicina, Ribeirão Preto, 36: 365-369, abr./dez. 2003.

RESUMO - A infecção do trato urinário (ITU) é mais freqüente no sexo feminino. Pode ser complicada, quando se associa a condição subjacente, que eleva o risco de falha terapêutica e, conseqüentemente, o tempo de tratamento necessário. O microorganismo que mais freqüentemente causa ITU é Escherichia coli. A ITU de repetição deve-se a inúmeros fatores, e deve ser investigada.

UNITERMOS - Infecção do Trato Urinário. Bacteriúria; profilaxia.

A infecção do trato urinário (ITU) é afecção muito comum, e responde por grande parte dos processos infecciosos, comunitários e hospitalares. Caracteriza-se pela presença de microorganismos nas vias urinárias, habitualmente, bactérias, seja na bexiga, próstata, sistema coletor ou rins ${ }^{(1)}$. Infecção por fungos é incomum, e costuma acometer pacientes imunossuprimidos, principalmente transplantados e portadores da Síndrome da Imunodeficiência Adquirida. Raramente, pode ocorrer infecção por vírus, ou mesmo acometimento do trato urinário na esquistossomose.

Incidência: varia de acordo com a faixa etária. É mais comum no sexo masculino, no primeiro ano de vida, devido à maior incidência de mal-formações congênitas, como válvula de uretra posterior, mal-formações da uretra (hipospádia, epispádia, etc.) Após tal período, passa a ser mais freqüente no sexo feminino. $\mathrm{Na}$ idade pré-escolar, tende a ser de 10 a 20 vezes maior em crianças do sexo feminino ${ }^{(1)}$. No adulto, a frequiência de ITU aumenta, também, com predomínio no sexo feminino, com picos de incidência, no início, ou relacionado com atividade sexual, na gestação e na menopausa. A incidência volta a aumentar no sexo masculino após a $5^{\mathrm{a}}$ e $6^{\mathrm{a}}$ década de vida, devido a problemas da próstata. A menor incidência de ITU, no sexo masculino, deve-se a fatores anatômicos: uretra mais longa, atividade bactericida do fluido prostático e ambiente periuretral mais úmido. No sexo feminino, além da uretra mais curta, há, também, maior proximidade do ânus com a uretra e o vestíbulo vaginal, o que possibillita a colonização destes por enterobactérias que, habitualmente, causam ITU.

Classificação: a ITU é classificada em complicada e não complicada. A ITU não complicada é no paciente com as seguintes características ${ }^{(1)}$.

- sexo feminino, não grávida;

- ausência de alterações anatômicas do trato urinário; - ausência de alterações funcionais do trato urinário;

- ausência de cateteres urinários;

- ausência de alterações da imunidade;

- adquirida na comunidade.

A ITU complicada associa-se com condição subjacente que eleva o risco de falha terapêutica:

- sexo masculino;

- obstrução urinária; 
- alterações anatômicas do trato urinário;

- alterações funcionais do trato urinário;

- patógeno multirresistente;

- corpo estranho;

- imunossupressão;

- cateteres urinários;

- presença de cálculos urinários e/ou nefrocalcinose.

Patogênese: os microorganismos uropatogênicos colonizam o intestino grosso e a região perianal. Nas mulheres, pode haver colonização do vestíbulo vaginal e do intróito uretral e, posteriormente, ocorre ascenção para a bexiga e/ou rins ${ }^{(2)}$. Em condições normais, há competição entre esses uropatógenos e a flora vaginal, constituída predominantemente por lactobacilos. A colonização da vagina é facilitada, principalmente, pelo uso de antibióticos e pela má higiene perineal. A migração para a uretra e bexiga é desencadeada, principalmente, pela atividade sexual, pelo uso de contraceptivos com espermicida, e pela alteração do $\mathrm{pH}$ vaginal, que pode ocorrer com a alteração da flora pelo uso de antibióticos e pelo hipoestrogenismo que, habitualmente, ocorre na menopausa ${ }^{(2)}$.

Microbiologia: as enterobactérias são as principais causadoras de ITU:

- Escherichia coli (> 85\% ITU comunitárias e 50\% ITU hospitalares)

- Staphylococcus saprophyticus

- Proteus sp

- Klebsiella sp

- Pseudomonas sp

- Serratia sp

- Enterobacter sp

- Enterococo, etc.

Fatores de virulência: as enterobactérias podem apresentar as seguintes estruturas ${ }^{(1,2)}$, relacionadas a seguir.

- Flagelo (antígeno H), responsável pela motilidade

- Cápsula (antígeno K), confere resistência à fagocitose

- Lipopolissacarídeo (antígeno O), determinante antigênico

- Hemolisina, toxina polipeptídica, que provoca lise de hemácias

- Aerobactina, quelante de ferro secretado, devido à importância deste no crescimento e divisão bacteriana
- Fímbrias, estruturas responsáveis pela aderência da bactéria ao urotélio e pela transmissão de informação genética para outras bactérias através dos plasmídeos. Há 2 tipos de fímbrias ${ }^{(2)}$ :

a) fímbria tipo I: o receptor é a manose ou a proteína de Tamm Horsfall,

b) fímbria P: liga-se ao grupo sanguíneo P, presente em hemácias e em células epiteliais, o receptor é parte de um glicoesfingolípide (Gal-Gal), associa-se com pielonefrite.

Diagnóstico laboratorial: o diagnóstico definitivo é firmado através do crescimento de microorganismos na urocultura. A bacteriúria significativa, habitualmente, caracteriza-se por crescimento bacteriano > 100.000 colônias $/ \mathrm{ml}$, porém valores mais baixos são aceitos em algumas situações ${ }^{(3)}$ :

- > 100 colônias/ml de coliformes em mulher sintomática;

- Qualquer crescimento em urina colhida através de punção suprapúbica;

- > 1000 colônias/ml em homem sintomático

A amostra de urina deve ser obtida através do método do jato médio e colhida com assepsia em pacientes que não apresentem anormalidades funcionais do trato urinário e, preferencialmente, a $1^{\mathrm{a}}$ urina do dia. Se não for colhida a $1^{\mathrm{a}}$ urina do dia, deve ser colhida amostra de urina com intervalo mínimo de $2 \mathrm{~h}$ após a última micção, o que corresponde ao período de latência para o crescimento bacteriano.

A presença de leucocitúria com agrupamentos, no exame de urina do tipo I, tem alta especificidade, principalmente se associar a sinais e/ou sintomas atribuíveis ao trato urinário, e é muito útil enquanto se aguarda a urocultura. A presença de nitrito no exame bioquímico da urina também é específica para infecção do trato urinário. Indica a presença de esterase leucocitária (ocorre quando há leucocitúria) ou atividade redutora de nitrato (causada por enterobactérias).

Síndromes clínicas: a ITU pode ser classificada do ponto de vista clínico em várias síndromes, como as indicadas a seguir.

- Cistite: também denominada ITU baixa, se caracteriza pela invasão e aderência de microorganismos na bexiga, levando a uma resposta inflamatória. Clinicamente caracteriza-se por presença de disúria, polaciúria, tenesmo vesical e dor hipogástrica. Cerca de 30\% das ITU baixas apresentam comprometimento alto oculto, e o tratamento nestes 
casos deve ser feito para ITU alta. O diagnóstico de ITU alta oculta deve ser feito, quando estiver presente um dos um dos fatores mencionados a seguir.

- Sexo masculino

- Idade avançada

- Infecção hospitalar

- Gravidez

- Cateter urinário

- Instrumentação recente do trato urinário

- Alterações anatômicas ou funcionais do trato urinário

- História de infecção do trato urinário na infância

- Presença de sintomas por 7 dias ou mais

- Uso recente de antibióticos

- Diabetes Mellitus

- Imunossupressão

- Pielonefrite: também denominada ITU alta e nefrite intersticial bacteriana, caracteriza-se pela invasão e aderência de microorganismos no rim, levando a uma resposta inflamatória. Clinicamente caracteriza-se por dor em flanco, sensibilidade na região lombar (sinal de Giordano), febre, calafrios, náuseas e vômitos.

- Bacteriúria assintomática: caracterizada pela presença de bacteriúria significativa em pacientes sem sintomas atribuíveis ao trato urinário. Para que se possa diferenciar da contaminação, deve ocorrer o crescimento do mesmo germe em 2 uroculturas e com contagem de colônias $>100.000 / \mathrm{ml}$ ou próxima a esse valor.

- Síndrome uretral: sintomas de disúria e pola-ciúria exuberantes, porém com urocultura negativa, e sedimento urinário normal ou com leucocitúria. Habitualmente, associa-se a infecções por germes não habituais (Chlamydia trachomatis, Ureaplasma urea-lyticum, Mycoplasma, Gonococo, Trychomonas, Cândida, Mycobacteria), e cistites não infecciosas.

Tratamento: deve ser feito de acordo com a localização e presença de fatores complicantes, tais como os relacionados a seguir.

- ITU baixa não complicada: deve ser tratada por 7 dias. As drogas mais indicadas são: norfloxacin (400mg VO 12/12 h), ácido pipemídico (400mg VO $12 / 12 \mathrm{~h}$ ), cefalexina (500mg VO 6/6 h), nitrofurantoína (100mg VO 6/6 h), e cefuroxima 250mg VO
$8 / 8 \mathrm{~h}$ ). As quinolonas são contra-indicadas na gravidez e em crianças com menos de 12 anos de idade. Em caso de recaída, o tratamento deve ser realizado por um período de 14 dias $^{(3)}$.

- ITU baixa comunitária em pacientes com sonda vesical: deve ser tratada por 7 dias. As drogas mais indicadas são: norfloxacin (400mg VO 12/12 h), ácido pipemídico (400mg VO 12/12 h), e cefuroxima (250mg VO 8/8 h).

- ITU baixa comunitária em gestantes: deve ser tratada por 7 dias. As drogas mais indicadas são: cefalexina (500mg VO $6 / 6 \mathrm{~h}$ ) e cefuroxima ( $250 \mathrm{mg}$ VO $8 / 8 \mathrm{~h}$ ).

- ITU alta comunitária (tratamento ambulatorial): deve ser tratada por 14 dias. As drogas indicadas pela Comissão de Uso e Controle de Antimicrobianos do HCRP são: norfloxacin (400mg VO 12/12 h) cefuroxima (250mg VO 8/8 h), e gentamicina (3mg/ $\mathrm{Kg} / \mathrm{dia} \mathrm{IM}$ em dose única). Na Divisão de Nefrologia da FMRP-USP, indicamos tratamento inicial com ciprofloxacin (500mg VO 12/12 h).

- ITU alta comunitária (tratamento hospitalar): a internação está indicada para pacientes com febre, toxemia e queda do estado geral, e o tratamento deve durar 14 dias. Deve ser iniciado por via EV e, quando houver melhora do estado geral, transferido para via oral. As drogas indicadas pela Comissão de Uso e Controle de Antimicrobianos do HCRP

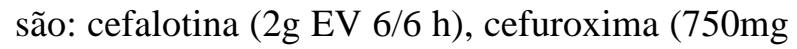
EV $8 / 8 \mathrm{~h}$ ), gentamicina ( $3 \mathrm{mg} / \mathrm{Kg} /$ dia IM) e ciprofloxacin (400mg EV 12/12 h). Na Divisão de Nefrologia da FMRP-USP indicamos tratamento inicial com ciprofloxacin (400mg EV 12/12 h até melhora clínica e 500mg VO 12/12 h até o término do tratamento).

- ITU alta comunitária em gestantes: o tratamento deve durar 14 dias. Deve ser iniciado por via EV, e quando houver melhora do estado geral, passar para via oral. As drogas mais indicadas são: cefalotina ( $2 \mathrm{~g}$ EV 6/6 h) e cefuroxima (750mg EV 8/8 h).

Recorrência: a recorrência pode se apresentar como:

- Recaída: presença do mesmo microorganismo, que não foi efetivamente eliminado. Ocorre até 2 semanas após o término do tratamento.

- Reinfecção: novo episódio de infecção, pelo mesmo ou por outro microorganismo. Sintomas reaparecem em período maior do que 2 semanas após o término do tratamento. 
Investigação por imagem do trato urinário: deve ser feita em pacientes do sexo masculino com ITU e em mulheres com ITU de repetição. Os exames para avaliação são os seguintes:

- Ultra-som de vias urinárias: exame não invasivo, habitualmente é o primeiro a ser realizado. Útil para mostrar cálculos, mal-formações, abcessos, rins policísticos e dilatação da árvore pielocalicial. Deve também ser usado como exame de triagem, para a indicação de outros exames mais sensíveis.

- Urografia excretora: não deve ser realizada na fase aguda da infecção, pois os resultados são ruins, além da nefrotoxicidade do contraste. Possui grande utilidade para o diagnóstico de alterações anatômicas, como dilatação pélvica, calicial e ureteral, estenose de junção uretero-piélica e duplicidade ureteral, entre outras.

- Uretrocistografia miccional: exame de escolha para o diagnóstico de refluxo vesicoureteral. Também tem grande utilidade para o diagnóstico de válvula de uretra posterior. Deve ser solicitado para crianças abaixo de 6 anos com ITU de repetição, no sexo feminino, e para qualquer episódio de ITU no sexo masculino, desde que não haja um diagnóstico prévio da causa. Não está indicado para adultos, a não ser em caso de ITU de repetição pós-transplante renal.

- Cintilografia com DMSA (ácido dimercaptossuccínico): é útil na detecção de cicatrizes renais em crianças com refluxo vesicoureteral. Pode, também, ser realizado na fase aguda de ITU em crianças, para detectar a presença de pielonefrite.

- Cistoscopia: indicada em pacientes idosos com ITU de repetição sem causa aparente, e em pacientes com hematúria, especialmente se houver história de tabagismo, para o diagnóstico de câncer de bexiga.

- Tomografia computadorizada: raramente é necessária. Útil, quando há suspeita de tumor renal ou de abcesso, e na investigação de rins policísticos.

ITU de repetição: é condição freqüente em pacientes do sexo feminino com investigação do trato urinário sem anormalidades. Tais pacientes apresentam maior maior susceptibilidade à colonização vaginal, mesmo em períodos assintomáticos. Existe uma maior propensão dos uropatógenos coliformes para aderir ao urotélio, em comparação com mulheres normais. Há vários fatores de risco ${ }^{(4)}$ :

- Genéticos e biológicos

Fenótipo não secretor do grupo sanguíneo $\mathrm{ABH}$ (maior tendência à aderência de uropatógenos) Receptor de IL-8
- Comportamentais

Ato sexual

Uso de contraceptivos com espermicida, no último ano

Novo parceiro sexual no último ano

Primeira infecção urinária antes dos 15 anos

Mãe com história de infecção urinária

- Anatomia pélvica: distância significativamente menor entre o ânus e a uretra

- Pós-menopausa

Incontinência urinária

Cistocele

Resíduo pós-miccional

Alteração do $\mathrm{pH}$ vaginal (associada a altera ções hormonais)

- Determinantes de virulência do uropatógeno

Estratégias de profilaxia da ITU de re-

petição: várias medidas podem ser adotadas, como as relatadas a seguir:

- Alteração do método contraceptivo

- Maior ingesta hídrica

- Micção pós-coital

- Estrogênios tópicos na vagina (pós-menopausa)

- Quimioprofilaxia

Contínua

Nitrofurantoína (100mg/dia)

Sulfametoxazol-trimetoprim (480mg/dia)

Norfloxacin $(400 \mathrm{mg} / \mathrm{dia})$

Ácido pipemídico (400mg/dia)

Pós-coital: mesmas drogas utilizadas na estratégia contínua

Auto-tratamento: tratamento de episódios, quando aparecem, sem profilaxia nos intervalos

Bacteriúria assintomática: o diagnóstico é firmado com 2 uroculturas positivas, com crescimento bacteriano > 100.000 colônias/ml ou próximo deste valor, com o mesmo agente nas 2 amostras. Sua incidência é maior em alguns grupos:

- Grávidas

- Idosos

- Diabéticos

- Transplantados

- Pacientes com cateteres urinários

- Crianças com refluxo vesicoureteral

- Pacientes com cálculos de estruvita, infectados

O tratamento é discutível em idosos e em mulheres em idade produtiva, pois o índice de recorrência é alto, e o tratamento não altera o prognóstico e a evolução. 
Os outros grupos, como os mostrados a seguir, devem ser sempre tratados:

- Pacientes grávidas devem ser sempre tratadas, pois o risco de trabalho de parto prematuro se eleva.

- Crianças com refluxo vesicoureteral, que não forem tratadas, desenvolvem cicatrizes renais. A condição exige tratamento, e a profilaxia deve ser feita a longo prazo para crianças com refluxo de graus I e II e algumas crianças com refluxo de grau III, até que o refluxo desapareça. Refluxo de graus IV e V e algumas crianças com refluxo de grau III devem ser submetidas a correção cirúrgica.

- Transplantados renais têm maior risco de desenvolver sépsis, devido à imunossupressão, e o risco de desenvolvimento de nefropatia crônica do enxerto também é mais elevado em pacientes não tratados.

- Diabéticos devem ser tratados, pois apresentam risco mais elevado de desenvolver complicações, como abcesso perinefrético, necrose de papila e pielonefrite enfisematosa.

- Pacientes com cálculo de estruvita devem ser tratados, porém os cálculos devem ser eliminados, senão o processo infeccioso perpetua-se.

-Pacientes com cateteres urinários apresentam risco de bacteremia por gram-negativos elevado em 5 vezes, e o aumento do risco é proporcional ao tempo de cateterização.

VIEIRA NETO OM. Urinary tract infection. Medicina, Ribeirão Preto, 36: 365-369, apr./dec. 2003.

Abstract - Urinary tract infection (UTI) is more frequent in female patients. It may be complicated, when associated with an underlying condition that increases the risk of therapeutic failure, and the length of treatment. The most frequent etiologic agent that causes UTI is Escherichia coli. The recurring UTI may be due to several factors, and must be investigated.

Uniterms - Urinary Tract Infection. Bacteriuria; prophylaxis.

\section{REFERÊNCIAS BIBLIOGRÁFICAS}

1 - CATTEL WR. Infections of the kidney and urinary tract. Oxford University Press, London, 1996. (Oxford Clinical Nephrology Series).

2 - SCHOOLNIK GK. How Escherichia coli infects the urinary tract. N Engl J Med 320: 804-805, 1989.
3 - HOOTON TM \& STAMM WE. Diagnosis and treatment of uncomplicated urinary tract infection. Infect Dis Clin North Am 11: 551-553, 1997.

4 - FOXMAN B. Recurring urinary tract infection: incidence and risk factors. Am J Public Health 80: 331-333, 1990. 